\title{
MAPA DE DANOS PARA EDIFÍCIOS HISTÓRICOS COM MANIFESTAÇÕES PATOLÓGICAS: ESTUDO DE CASO DA CATEDRAL NOSSA SENHORA DAS MERCÊS EM PORTO NACIONAL (TO)
}

\section{DAMAGE MAP FOR HISTORICAL BUILDINGS WITH PATHOLOGICAL MANIFESTATIONS: CASE STUDY OF OUR LADY OF THE MARKET CATHEDRAL IN PORTO NACIONAL (TO)}

\author{
SANTOS, C. A. \\ Engenheira Civil \\ ITPAC PORTO \\ Tocantins, Brasil \\ santos.manduca@hotmail.com
}

\author{
SANTOS, D. F A. \\ Professor \\ ITPAC PORTO \\ Tocantins, Bras \\ eng.prof.santos@gmail.com
}

\section{RESUMO}

A elaboração de um mapa de danos, principalmente em edifícios históricos, serve como ferramenta que auxilia na preservação e conservação do mesmo. A partir de pesquisa documental, inspeções e depoimentos, foi elaborado um mapa de danos como ferramenta de identificar as manifestações patológicas encontradas, possibilitando medidas de profilaxia. O fato de a igreja ser tombada pelo IPHAN (Instituto do Patrimônio Histórico e Artístico Nacional), dificultou a realização de ensaios mais complexos. O estudo mais aprofundado das técnicas construtivas e dos materiais utilizados na época na região foi essencial para um diagnóstico mais preciso. Logo, a ausência de uma norma que padroniza a realização de mapa de danos de construções históricas se fez necessário, uma vez que se teve que utilizar o uso do senso como princípio da realização deste artigo.

Palavras-chave: Mapa de danos, Manifestações Patológicas, Patrimônio Histórico

\begin{abstract}
The elaboration of a damage map, mainly in historical buildings, serves as a tool that helps its preservation and conservation. From documentary research, inspections and testimonials, a damage map was prepared as a tool to identify the pathologies found, enabling prophylaxis measures. The fact that the church is listed by the IPHAN (Institute of National Historical and Artistic Heritage) made it difficult to perform more complex essays. Further study of the construction techniques and materials used at the time in the region was essential for a more accurate diagnosis. Therefore, the absence of a norm that standardizes the mapping of damage of historical buildings was necessary, since it was necessary to use the use of sense as the principle of this article.
\end{abstract}

Keywords: Damage map, Pathological Manifestations, Historical Heritage.

\section{INTRODUÇÃO}

O estudo de manifestações patológicas em edifícios históricos, além de grande importância para a conservação de um bem cultural, é fundamental para que este seja restaurado de forma correta e eficaz diante dos problemas evidenciados. Neste contexto destaca-se que as ocorrências de problemas patológicos em edificações históricas são mais frequentes, devido a maioria se encontrar em grau de deterioração elevado, em função da falta de manutenção e de obras de conservação (BARBOSA et al., 2010).

As edificações históricas, por possuírem estilos característicos, devem ser estudadas de forma distinta das comuns. As construídas no Brasil geralmente seguem padrões arquitetônicos estrangeiros. A edificação abordada no presente trabalho não poderia ser diferente, seguindo um padrão francês.

Para um diagnóstico correto é imprescindível a caracterização da estrutura, bem como o conhecimento da sua história, projeto e intervenções, sendo necessárias pesquisas tanto em acervos quanto recolhimento de informações através de depoimentos de pessoas envolvidas.

Para a conservação da Catedral Nossa Senhora das Mercês, localizada no munícipio de Porto Nacional - TO, a criação de um mapa de danos documento elaborado através de levantamento das medidas da edificação, bem como, de vistorias e inspeções, é vital para a investigação da evolução dos problemas patológicos (TIRELLO; CORREA, 2011). 
A ausência de normativas brasileiras para a elaboração mapas de danos é um obstáculo, no entanto, pode ser superado através de pesquisas técnicas e acadêmicas e com a contribuição que vem sendo realizada pelo CECI (Centro de Estudos Avançados da Conservação Integrada).

\section{METODOLOGIA}

\subsection{CARACTERIZAÇÃO DO OBJETO DE ESTUDO}

\subsubsection{Histórico da Catedral}

A construção da Catedral foi iniciada em 1894 após os frades dominicanos perceberem que a capela antes construída não conseguia mais abrigar o número de fiéis. Pesquisadores afirmam que a conclusão foi no ano de 1903, porém em algumas fotos de anos posteriores ainda pode ser verificado que o teto da edificação não estava totalmente concluído, tendo fim apenas no ano de 1915 (MANDUCA, 2007).

Parte dos recursos veio da França, outra parte dos devotos, padres e alguns comerciantes, sem visar lucro. As ferramentas e materiais foram trazidos da França, de Belém, de municípios vizinhos pelo rio Tocantins, e algumas com origem na cidade. Pelas redondezas foram exploradas pedreiras para a retirada das pedras que seriam utilizadas na construção. Telhas e tijolos foram fabricados em olarias em Ribeirão dos Potes local de excelente barro situado do lado oposto do rio (OLIVEIRA, 1997).

O estilo barroco característico da época de colônia foi deixado de lado e predominou o estilo românico de Toulouse, originário da França, não se sabe ao certo quem foi o responsável pelo projeto, porém o frei Andre Blatgé se destacou devido ter sido considerado um arquiteto e construtor de talento já tendo feito antes outra obra importante (AUDRIN, 2007).

Em 20 de Dezembro de 1915 foi nomeada Diocese de Porto Nacional pela sua Santidade o Papa Bento XV pela bula “Apostulatus Officium", atendendo pedidos dos portuenses. Em 2008 considerada patrimônio histórico foi tombado pelo Instituto do Patrimônio Histórico e Artístico Nacional (IPHAN).

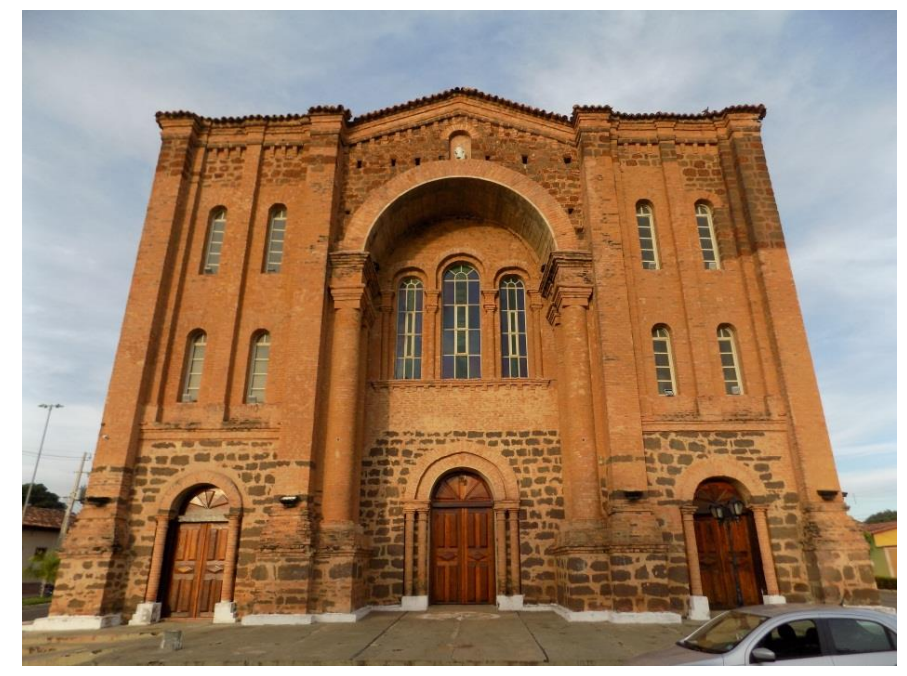

Figura 1: Catedral 2018

\subsubsection{Intervenções}

A Catedral por possuir uma estrutura robusta, sobreviveu por anos sem intervenções. A maior parte das obras de manutenção foi de pequenos reparos que são realizadas as vésperas dos festejos da Padroeira.

Antes da década de 1950 não se tem notícias nem registros de intervenções ocorrentes, porém neste mesmo ano foi necessária a retirada de retábulos de madeiras por estarem infestados de cupins. Em 1970 de forma equivocada foram colocadas barras de ardósia nas paredes internas e nas colunas a fim de proteger a edificação de sujeira. Depois deste acontecido um mestre de obras local erroneamente colocou argamassa de areia e cimento nas juntas da parte externa da igreja a uma determinada altura alegando que isso vedaria e evitaria a entrada de umidade. De 1997 a 2002 foram feitas obras de reparo em todo telhado que se encontrava bastante deteriorado devido ao tempo de exposição aos agentes agressivos, o piso foi todo trocado voltando ao modelo original, e o principal motivo do reparo foi devido o arco da 
fachada principal apresentar fissuras que comprometiam a segurança dos fiéis, este foi estabilizado com a construção de um sub-arco em concreto armado (MANDUCA, 2007).

Frequentadores da igreja relataram a presença excessiva de pombos e morcegos no local, notado pela existência de fezes e mau cheiro em vários cômodos, oferecendo desconforto e risco à saúde destas pessoas. Com o período de chuva o quadro se agrava (LAGO, 2016).

\subsubsection{Arquitetura da Catedral}

A Catedral foi toda construída em pedra e tijolos (adobe) assentes com argamassa de cinza, areia e água, amassada com os pés dos ajudantes. Na base foi usado o arenito que é comumente encontrado em ambientes de lagos e rios, é uma rocha sedimentar que apresenta uma boa resistência à compressão. $\mathrm{Na}$ parte superior os tijolos de barro de alta resistência e a pedra canga foram empregados, sendo técnicas de construção do período colonial promovendo uma característica original. Fundações com mais de dois metros de profundidade situadas num terreno plano acima das margens do rio Tocantins. Os pilares internos foram feitos somente de pedras emparelhadas para uma maior rigidez, são nitidamente desalinhados onde suas simetrias variam bastante, assim como as paredes que ora são robustas ora mais estreitas em torno de um metro de espessura (MANDUCA, 2007).

As fachadas não receberam revestimentos para não deixar de lado o estilo românico, o piso todo feito em lajotas cerâmicas de barro cozido. O telhado todo aparente formado por tesouras, terças, frechais, caibros e ripas, possui forro apenas no altar principal (OLIVEIRA, 1997).

A edificação possui aproximadamente $825,43 \mathrm{~m}^{2}$ de área construída, dividida em três naves, uma delas a principal com o pé direito maior do que as outras, um altar principal e dois secundários, uma sacristia, uma sala, um coro que foi construído no nível das torres sendo uma delas a do sino. As divisões das salas, dos altares e das naves não foram feitas em um só parâmetro possuindo assim dimensões variáveis, não possui o alinhamento da estrutura e paredes o que pode ser notado na planta baixa apresentada na Figura 2.
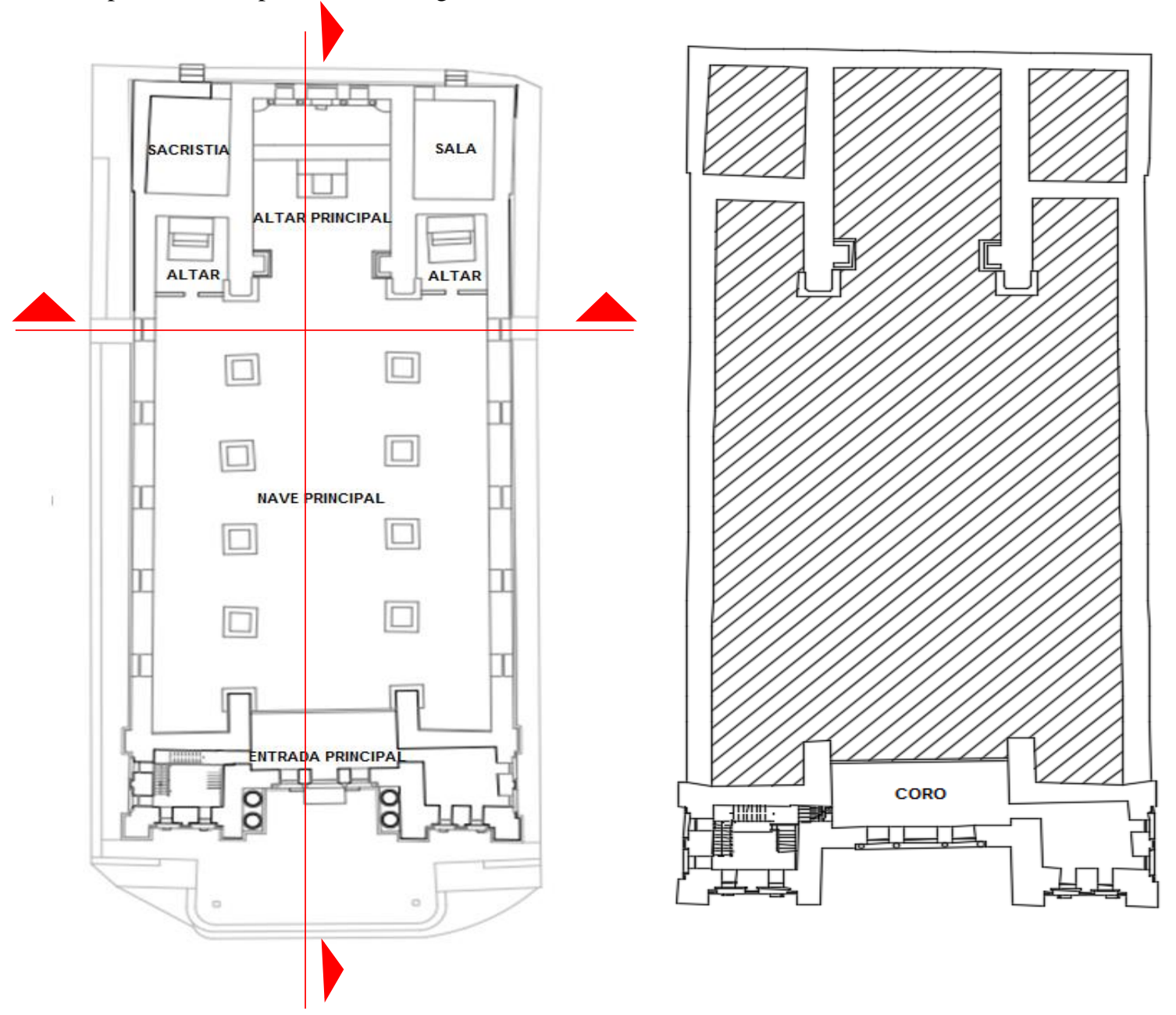

Figura 2: Planta baixa pavimento térreo e superior respectivamente. 


\subsection{MANIFESTAÇÕES PATOLÓGICAS DETECTADAS}

Para a elaboração do mapa de danos foram seguidas as seguintes etapas: Identificação das manifestações patológicas, fotografia das problemáticas, elaboração de uma Ficha de Identificação de Danos (FID) internas e externas, e marcação de plantas baixas e fachadas.

$\mathrm{Na}$ etapa de identificação das manifestações patológias existentes, foram realizadas inspeções visuais na igreja utilizando tecnologias que permitia ver de perto as problemáticas encontradas principalmente perto do telhado; no mesmo momento foi possível a execução da segunda etapa, retirando as fotos do local dando ênfase nas manifestações patológicas; na terceira etapa, servindo como auxílio para a produção do Mapa de Danos foram realizadas as FID'S.

Vale ressaltar que as fichas de identificação de danos foram executas no primeiro semestre de 2018 com a possibilidade de aparecimento de novas manifestações patológicas ou o desenvolvimento das existentes, quando submetidas à um ambiente propício.

Destaca-se que todo o estudo foi embasado no recolhimento de informações da história visando técnicas construtivas, através de documentos, depoimentos, e de visitas à Igreja, sendo feita de forma não destrutível, que é considerada por (TINOCO, 2009) um método indireto de inspeção, interpretando os dados para que as possíveis causas das manifestações fossem apresentadas e seu diagnostico fosse preciso.

Desta forma analisando as fachadas se destacaram a ocorrência das respectivas manifestações patológicas em todas elas: manchas de umidade, ferrugem nas esquadrias, e desplacamento dos tijolos. As figuras a seguir apresentam as Fichas de Identificação de Danos de forma resumida. Para cada anomalia encontrada foram relacionados símbolos e hachuras concebidas pela Autora com base no trabalho de E. A. Rocha, J. V. S. Macedo, P. Correia, E. C. Barreto Monteiro que fez uma adaptação de Mapa de Danos Para a Igreja do Carmo em Olinda PE.

Na Figura 3 de uma forma breve foram identificadas as anomalias existentes na Fachada Principal ou Fachada Oeste, onde foram encontradas, além das usuais, telhas arrancadas aparentemente pelos pombos que se agrupam ali ou por intempéries, sinais de vandalismo onde um poste foi retirado, parte das juntas de argamassa nas colunas da entrada principal estão descolando, possivelmente pela deficiência da argamassa junto com o grande fluxo de pessoas e materiais que passa por ali.

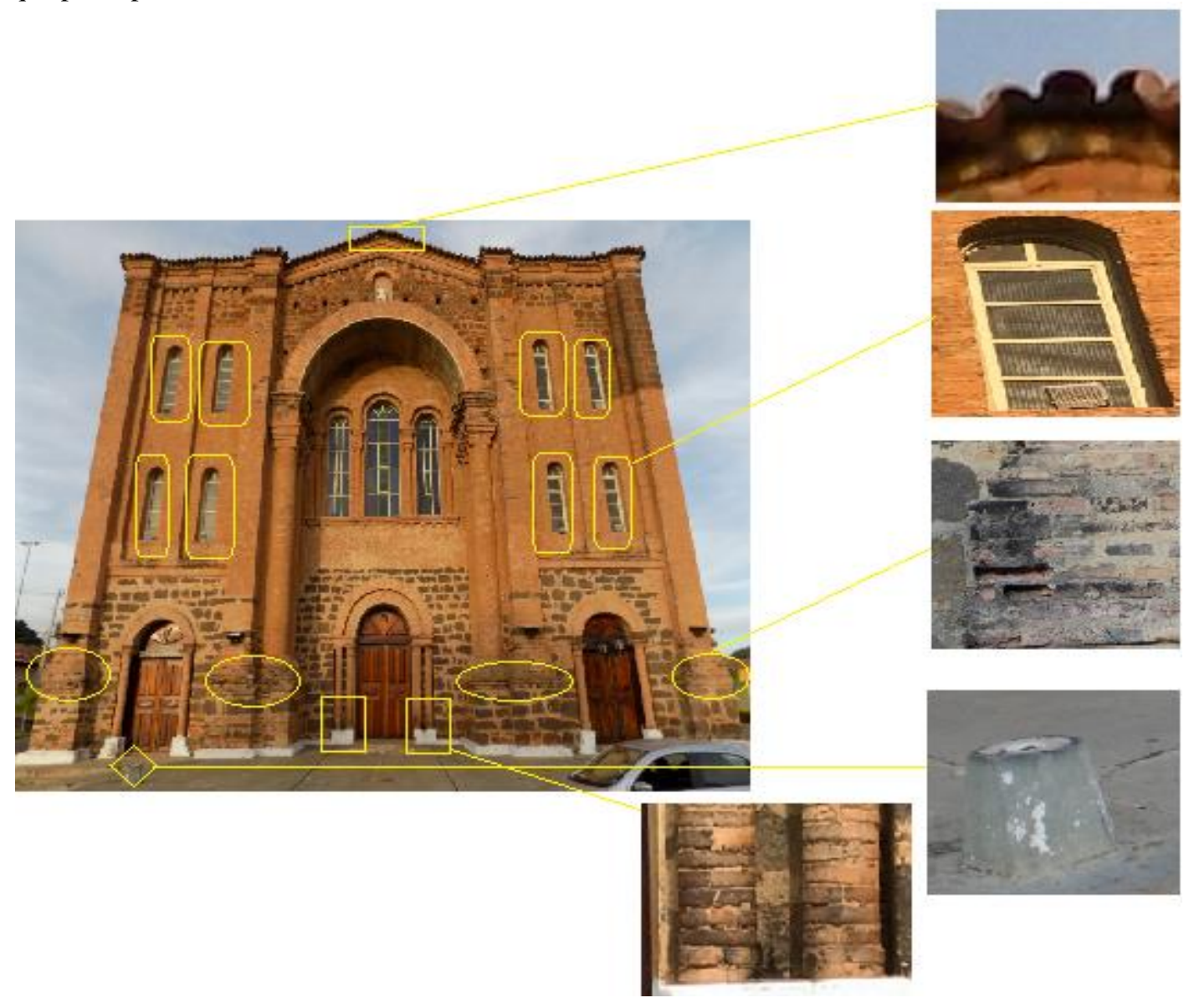




\section{СВРAT 2020 \\ concersso ans \\ DE 15 A 17 DE ABRIL | FORTALEZA - CE

\begin{tabular}{c}
\hline DANOS \\
\hline FERRUGEM \\
\hline DESPLACAMENTO DE TIJOLOS \\
\hline DESPLACAMENTO DE ARGAMASSA \\
\hline VANDALISMO \\
\hline DESTELHAMENTO
\end{tabular}

Figura 3: Ficha de Identificação de Danos da Fachada Oeste/Principal

A Figura 4 representa a Fachada Norte, a predominância é de manchas de umidade principalmente nas juntas de argamassa supostamente por ser muito porosa, e nos peitoris das janelas a provável causa seria acúmulo de água. Além destas anomalias foi encontrada marca de vandalismo, um agente de degradação comum em edificações.
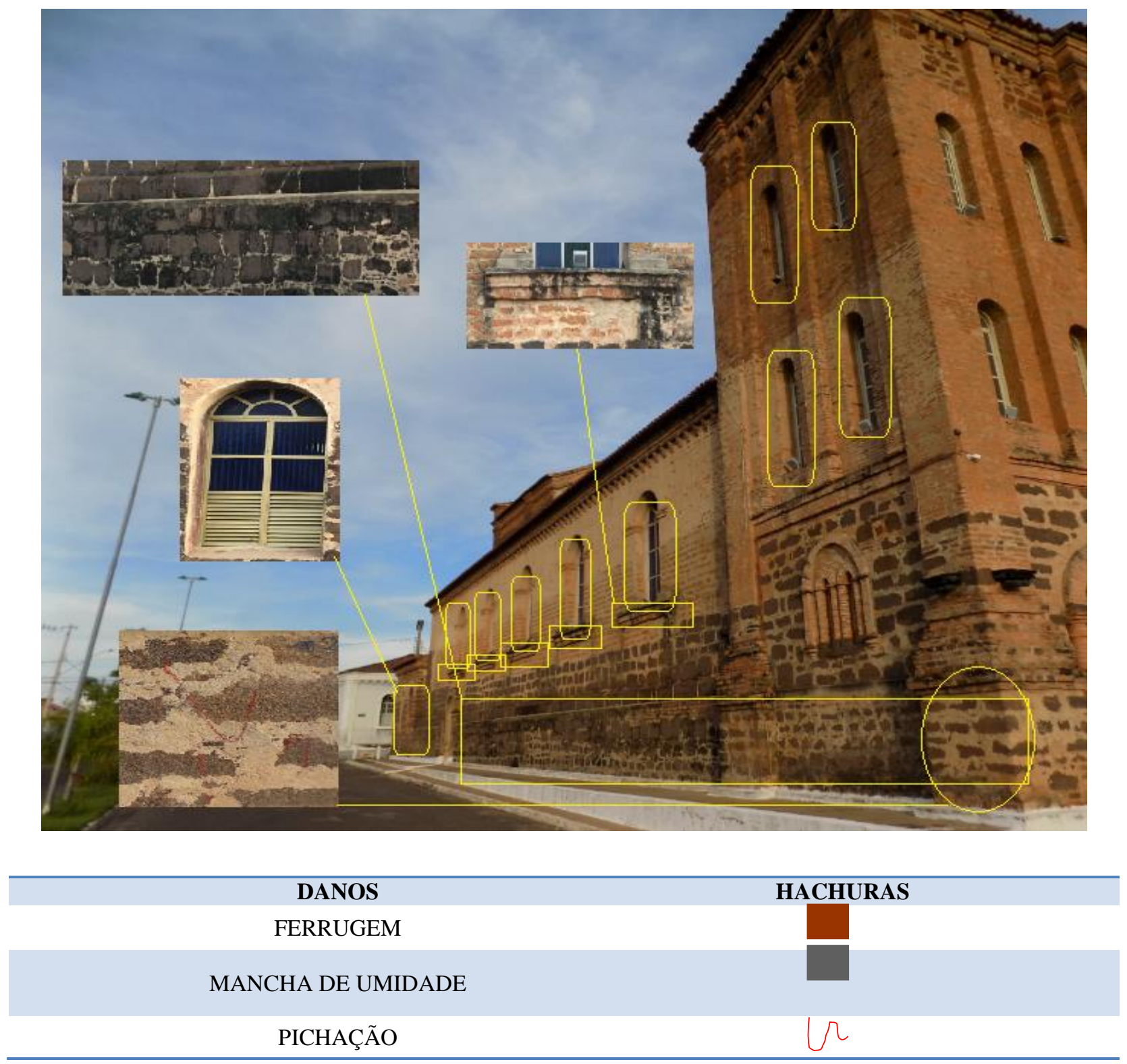

Figura 4: Ficha de Identificação de Danos da Fachada Norte 
Na Fachada Leste conforme a Figura 5 pode ser verificado manchas de umidade geradas pela proliferação de algas e fungos, manifestações patólogicas conhecidas como limo e bolor, respectivamente, uma com aspecto esverdeado e outra esbranquiçado, as condições do local são favoráveis pelo fato da umidade em si, e pela insuficiência de luz solar nesta fachada durante o dia.

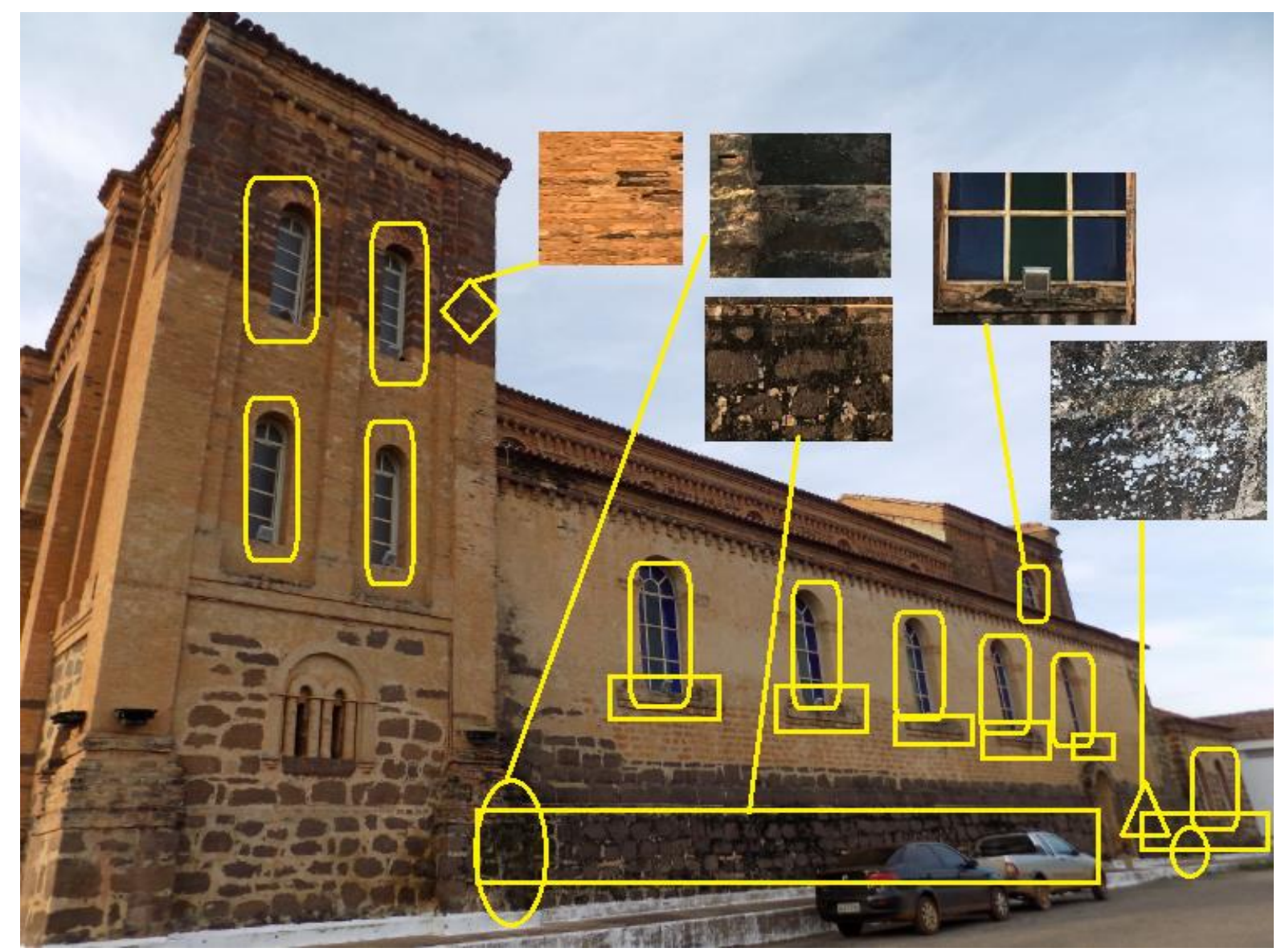

\begin{tabular}{c}
\hline DANOS HACHURAS \\
BOLOR \\
LIMO \\
FERRUGEM \\
MANCHA DE UMIDADE \\
\hline DESPLACAMENTO DE TIJOLO \\
\hline
\end{tabular}

Figura 5: Ficha de Identificação de Danos da Fachada Leste

Na Fachada Sul como pode ser observado na Figura 6 ocorrências de vegetação de pequeno porte, onde naquele ambiente encontraram substratos e nutrientes para se desenvolverem, mostrando a negligencia e falta de manutenção dos responsáveis pela igreja, estas patologias provocaram neste local danos ao telhado. 

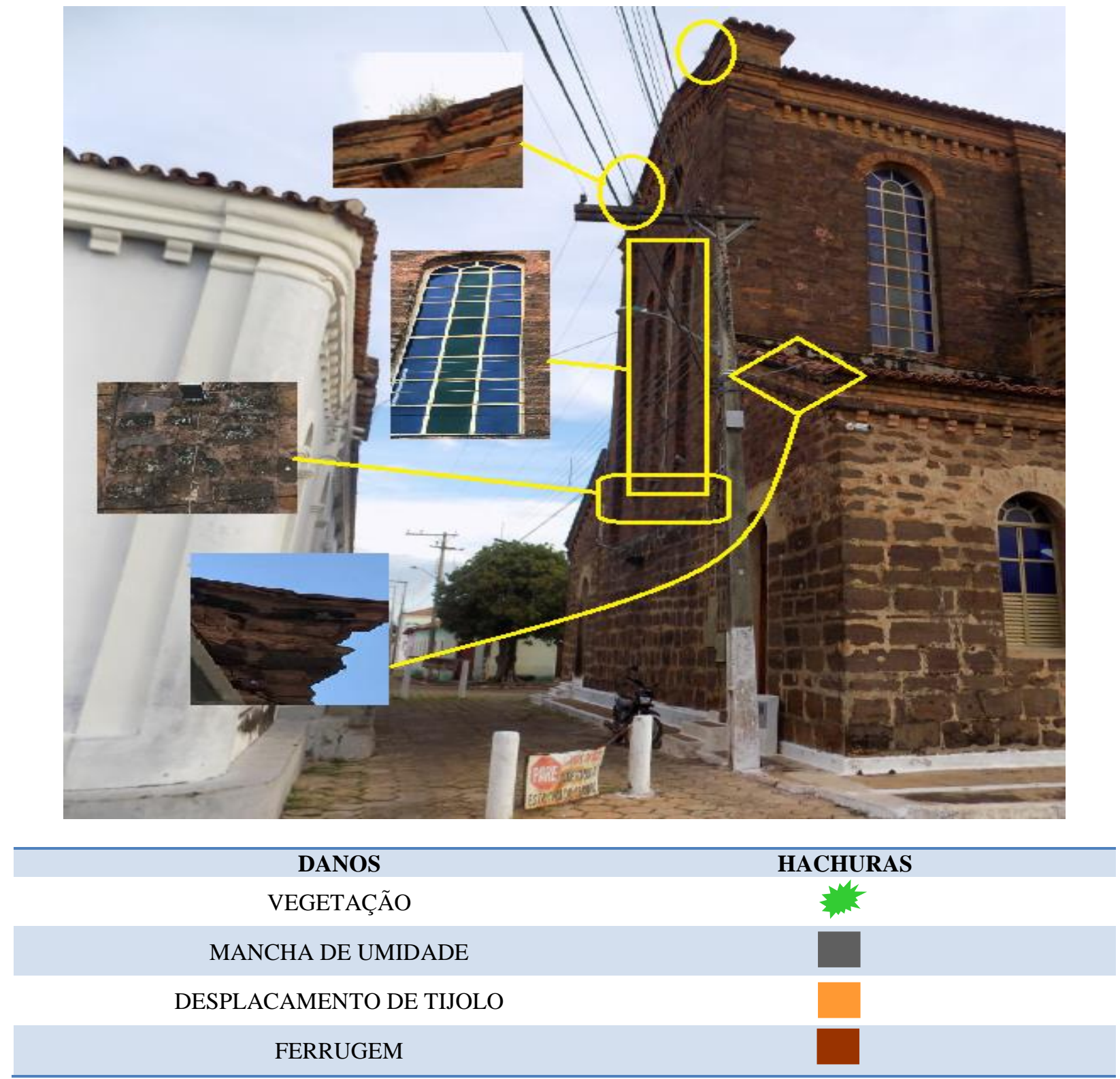

Figura 6: Ficha de Identificação de Danos da Fachada Sul

Após a análise de todas as fachadas um fato que chamou a atenção foi o notável número de pombos que se encontram ali, estes animais apesar de pequeno porte podem danificar elementos da edificação, principalmente no telhado gerando uma série de problemas provocados pela infiltração de água. Foi observado também que os descolamentos de tijolos ocorreram onde havia rebuscamento de detalhes, levando a crer que a causa principal seriam a exposição maior destes locais às intempéries.

Quanto aos danos ocorrentes no interior da edificação a maioria tem como causa o excesso de umidade que entra no local. Várias partes da pintura nas paredes estão empoladas, algumas já chegaram à perda de aderência em placas como pode ser observado na entrada da escadaria do sino. Manchas de umidade conjunta com fezes de morcegos podem ser encontradas no altar principal e no altar da direita. As madeiras do forro, do Coro e da escadaria estão visivelmente deterioradas por fungos ou cupins que tem como principal causa o acesso facilitado da umidade no interior da Igreja. Na Figura 7 pode ser observada a marcação de alguns locais em que as manifestações patológicas citadas acima são encontradas. 


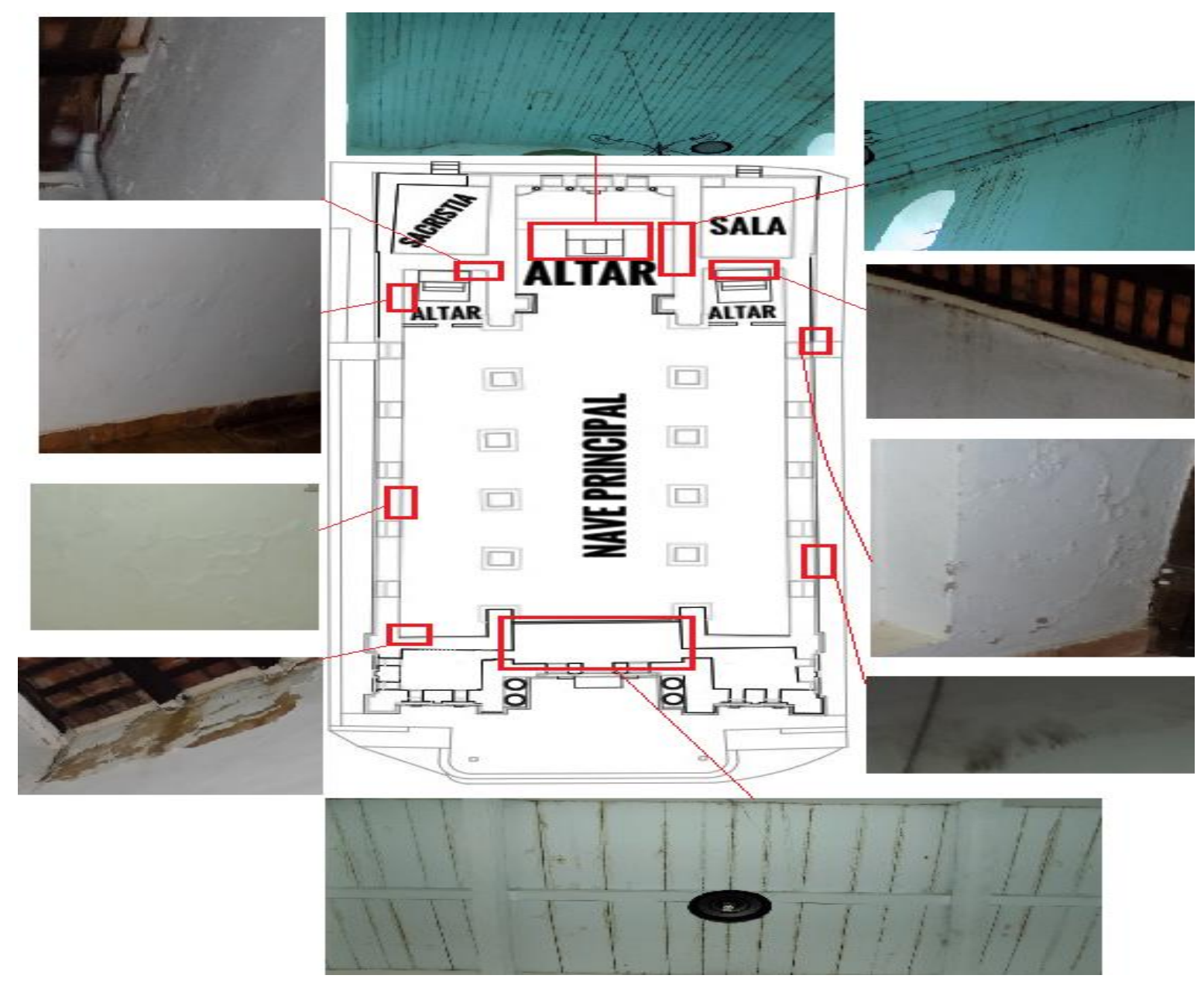

DANOS

HACHURAS

\begin{tabular}{c}
\hline EMPOLAMENTO DA PINTURA \\
DESPLACAMENTO DA PINTURA \\
MANCHA DE UMIDADE \\
SUJEIDADE \\
DEGRADAÇÃO DA MEDEIRA \\
FERRUGEM \\
\hline
\end{tabular}

Figura 7: Ficha de Identificação de Danos no interior da Catedral

\section{RESULTADOS E DISCUSSÃO}

Com intuito de mostrar gráfico-fotográfica minuciosamente o estado real em que se encontra a Catedral, e com a finalidade de auxiliar na preservação da edificação foi elaborado o Mapa de Danos, usando como suporte as FID'S, os dados históricos e as técnicas construtivas da época. O mapeamento de danos se distingue do mapa de danos pelo fato de ser as fases que são necessárias para a confecção do mapa em si como vistorias e a produção com as informações obtidas nas pesquisas (TINICA, 2009).

Para a elaboração deste Mapa de danos, os estudos minuciosos quanto ao tipo de construção e a época em que ela foi fundada foram vitais, pois com maior conhecimento dessas técnicas as manifestações patológicas foram reconhecidas com uma maior facilidade.

Com a simbologia respectiva a cada patologia as Figuras 8, 9, 10, e 11 apresentam os mapas de danos produzidos para as Fachadas Oeste, Norte, Leste e Sul, respectivamente, da Catedral Nossa Senhora das Mercês. 

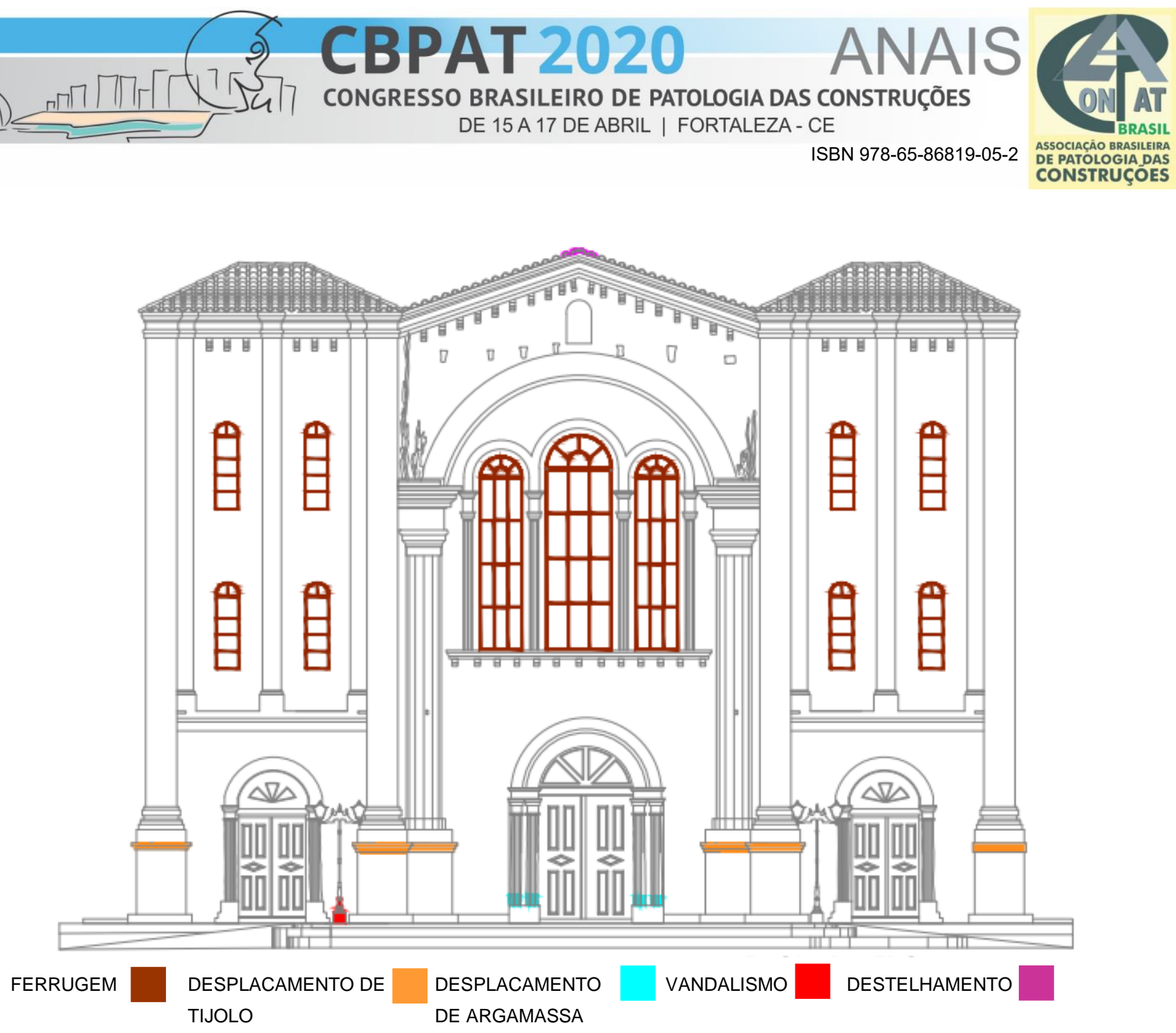

Figura 8: Mapa de Danos da Fachada Oeste

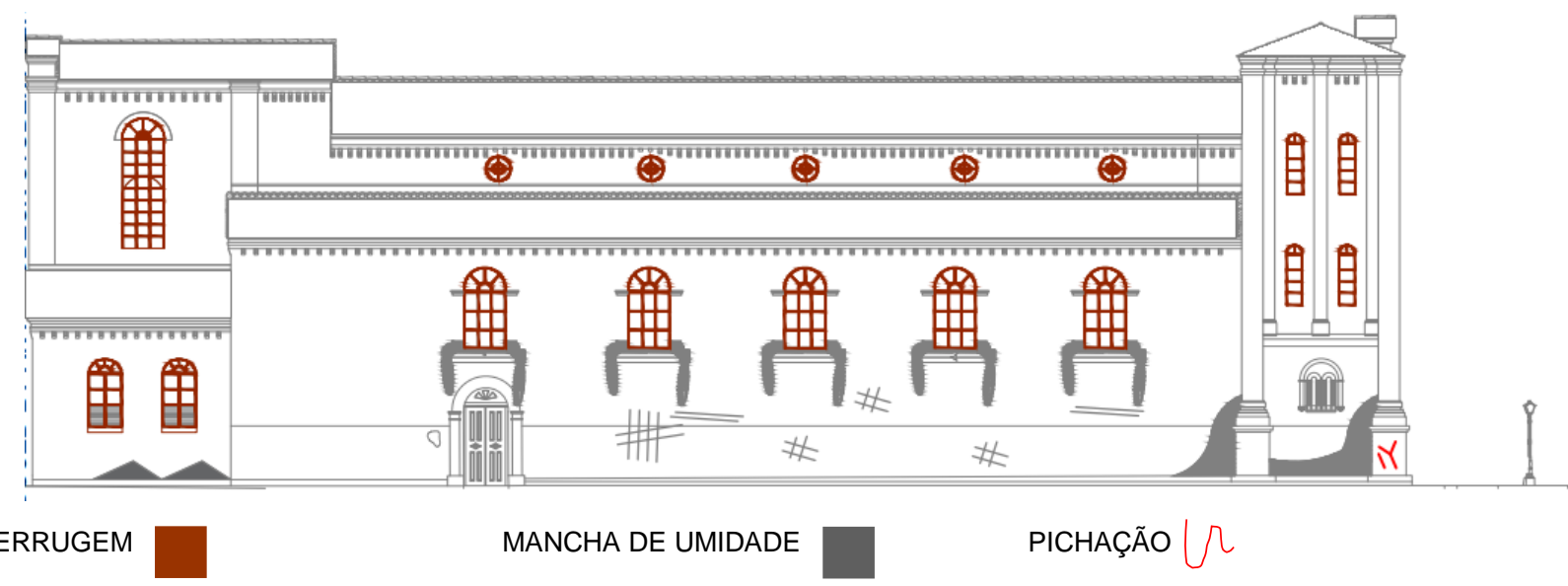

Figura 9: Mapa de Danos da Fachada Norte 


\section{СВРAT 2020 \\ CONGRESSO BRASILEIRO DE PATOLOGIA DAS CONSTRUÇÕES \\ DE 15 A 17 DE ABRIL | FORTALEZA - CE}

ISBN 978-65-86819-05-2

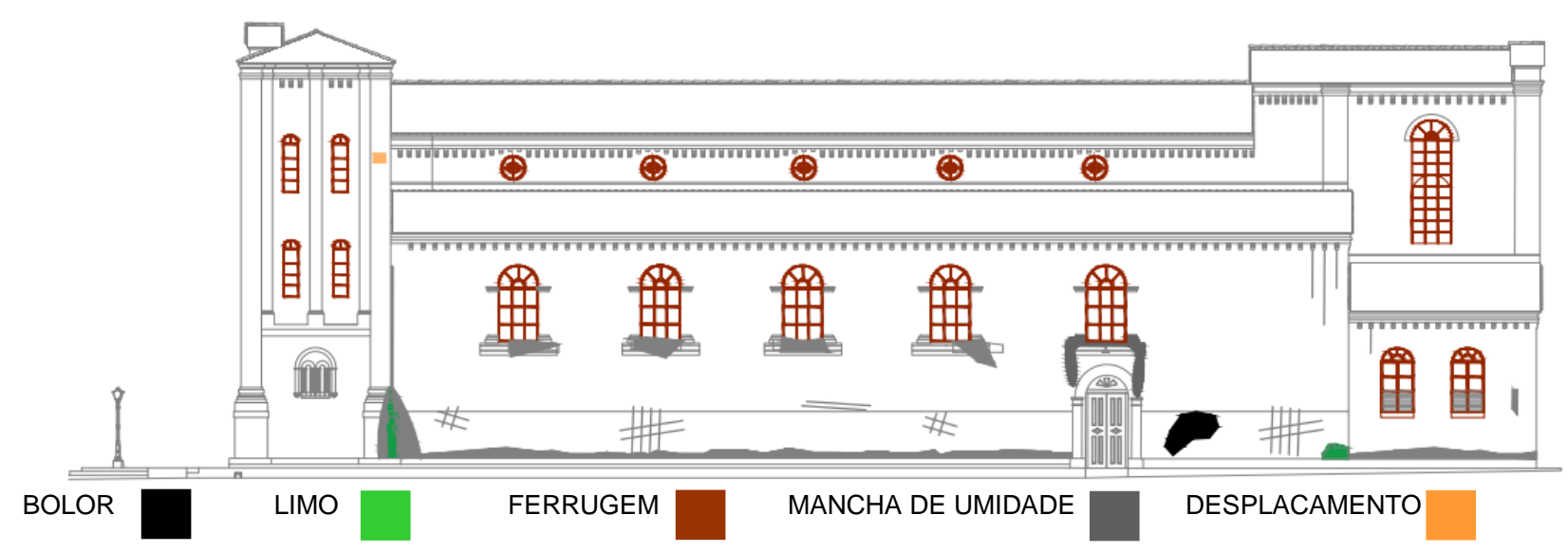

Figura 10: Mapa de Danos da Fachada Leste

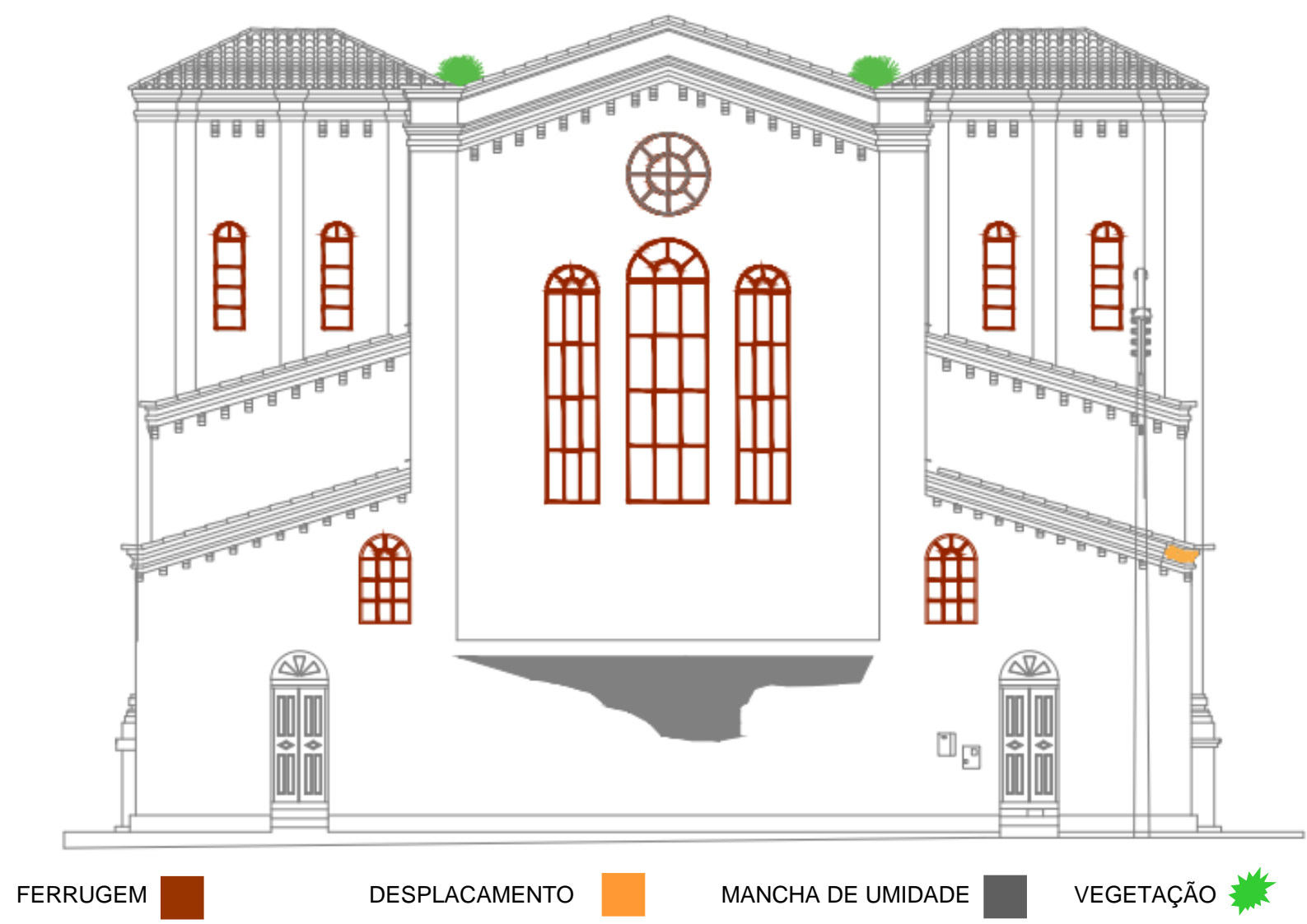

Figura 11: Mapa de Danos da Fachada Sul

Importa ressaltar que o mapa de danos apresentado na Figura 8 apoiou-se nas informações obtidas pelo FID da Figura 3 , a Figura 9, por sua vez considerou as observações apresentadas no FID da Figura 4, a Figura 10 teve como base as informações do FID na Figura 5 e o mapa de danos da Figura 11 foi elaborado a partir dos dados contidos no FID da Figura 6.

Nas Figuras 12 e 13 correspondem aos cortes AA e BB respectivamente são representadas as manifestações ocorrentes no interior da edificação com suas respectivas simbologias. 


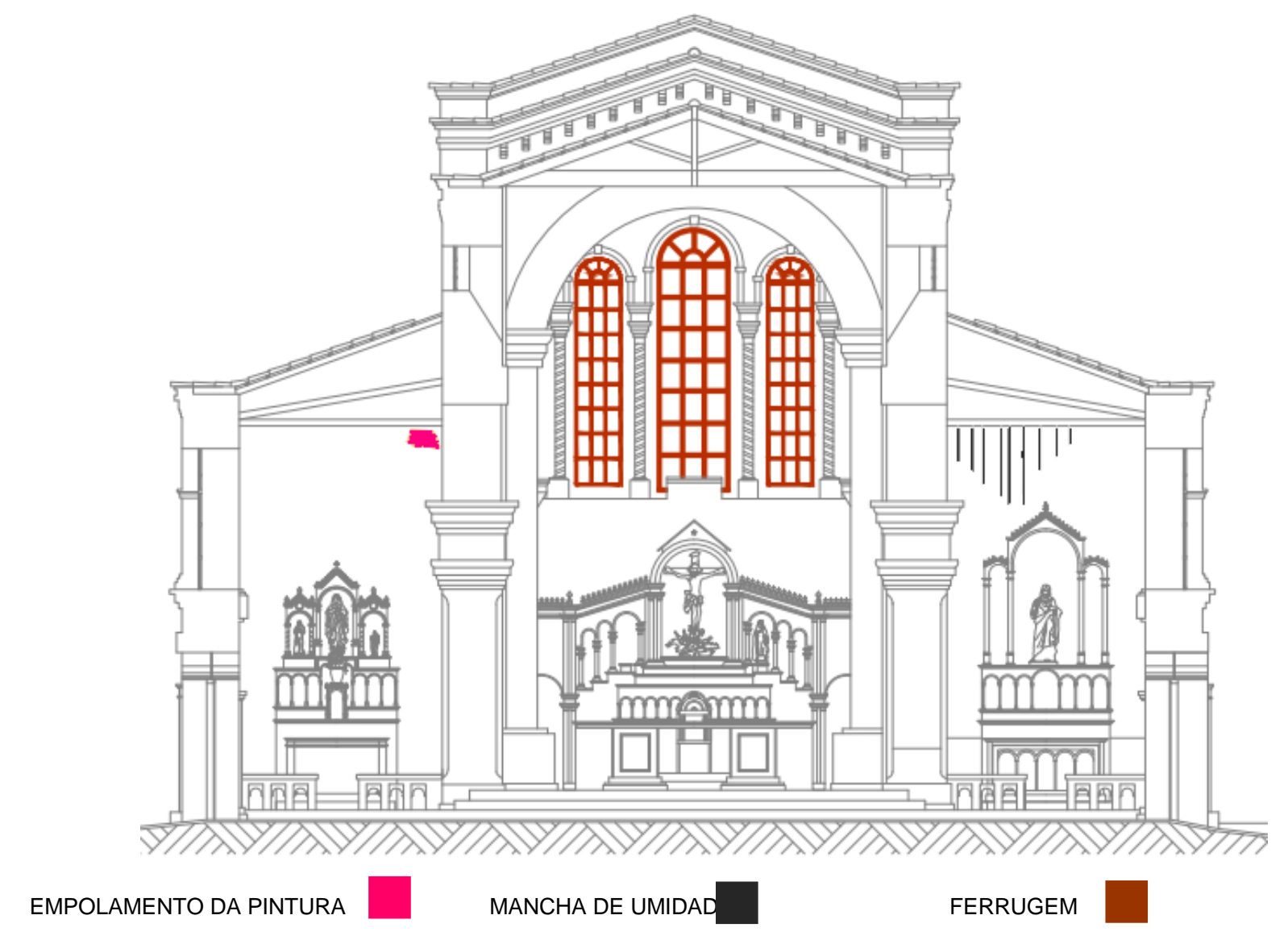

Figura 12: Mapa de Danos do corte AA

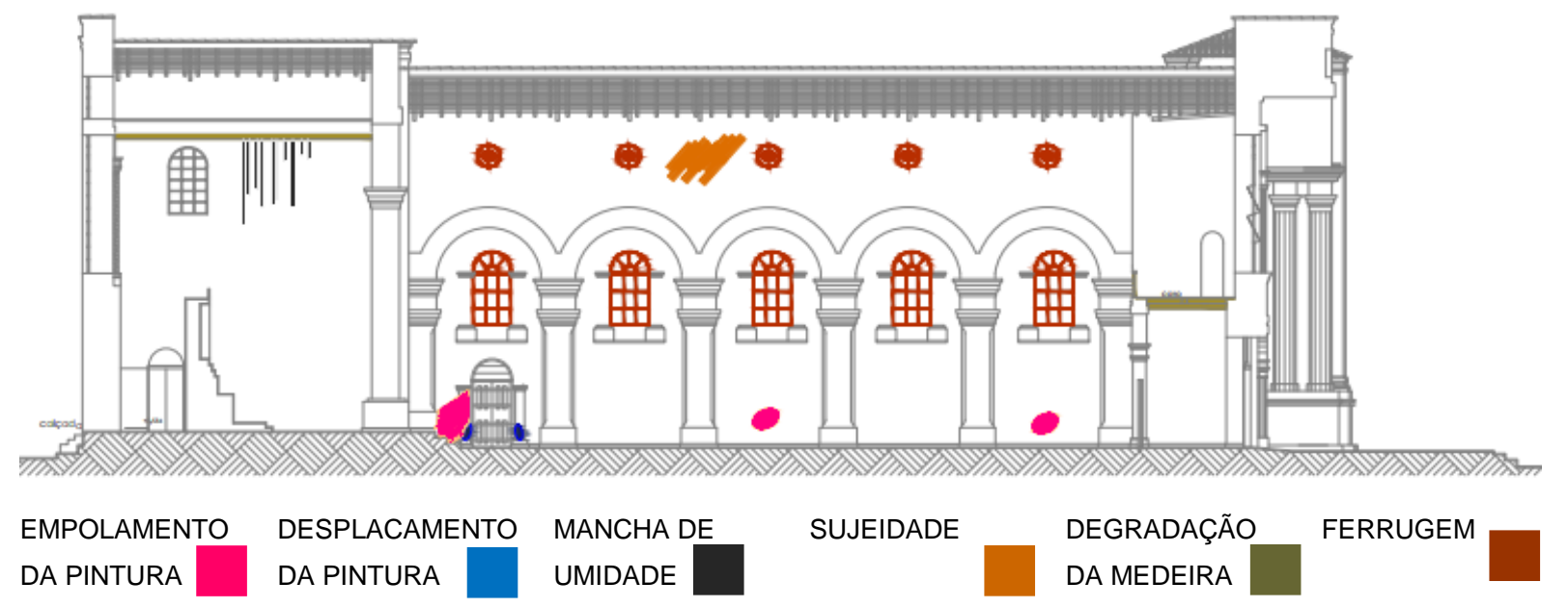

Figura 13: Mapa de Danos do corte BB

Logo a Figura 12 é com base no FID da Figura 7 e a Figura 13 se baseia na Figura 8. As análises foram feitas com base nos condicionantes que atuam no local e fazem com que estas patologias sejam manifestadas, este Mapa ajudará na supervisão da evolução dessas "doenças", facilitará os futuros estudos ou até mesmo intervenções preventivas ou corretivas que possam ser necessárias na igreja.

Sabe-se que a análise da origem da manifestação patológica é crucial para que haja uma conduta de intervenção própria do problema encontrado a fim de que se faça um restauro na estrutura que garanta o não aparecimento da mesma anomalia aumentando assim a vida útil da estrutura.

Observou-se a ocorrência de corrosão nas janelas das Fachadas, o que leva a crer que ocorreu devido a umidade, mostrando a importância do conhecimento do ambiente ao qual a edificação está inserida. Sendo assim, a análise dos condicionantes para o desenvolvimento da anomalia é essencial para diagnosticar o problema. 
A elaboração de Fichas de Identificação de Danos - FID colabora ativamente na análise do problema patológico e ao mesmo tempo constitui ferramenta fundamental para que se tenha um registro documental das visitas feitas e das anomalias encontradas. Após a elaboração da FID, a criação de mapas de danos vem para corroborar na visualização de cada manifestação patológica, criando uma ficha de controle das dimensões destas lesões nas fachadas e interiores. Isto auxilia de forma significativa na determinação do melhor procedimento de terapia para os problemas estudados, assim como possibilita identificar o melhor plano de ação para a recuperação e/ou restauração do bem analisado.

\section{CONCLUSÃO}

Por fim, é de grande importância o acompanhamento de edificações históricas por meio do mapa de danos, este que auxilia nas possíveis intervenções que o local poderá sofrer, sendo de manutenção ou de recuperação, pois neste documento estarão agrupadas informações que podem premeditar uma possível falência da estrutura. Os órgãos responsáveis pelos patrimônios históricos deveriam estar mais presentes quanto a fiscalização, e se necessário executando obras para melhorias desses bens, sem que o descaso se sobressaia como é visto habitualmente.

A criação de uma norma Brasileira que padronize a execução do Mapa de Danos de construções antigas facilitaria no trabalho de engenheiros e arquitetos que buscam preservar a história, pois seriam norteados de modo em que esses documentos fossem aceitos em qualquer órgão.

\section{REFERÊNCIAS}

RECICLANIP. Evolução dos pontos de coleta. Disponível em: <http://www.reciclanip.org.br>. Acesso em: 19 nov. $2017 \mathrm{~b}$.

AUDRIN, J. M.. Entre Sertanejos e Índios do Norte (1946)- Edições Púgil Ltda, Livraria Agir Editora- Rio de janeiro, 2007.

BARbosA, Maria Teresa Gomes et al. Patologias de Edifícios Históricos Tombados. Encontro Nacional da Associação Nacional de Pesquisa e Pós-graduação em Arquitetura e Urbanismo. (ENANPARQ), 2010.

BARThEL, C. et al. O Papel do Mapa de Danos na Conservação do Patrimônio Arquitetônico. In 1er. CONGRESO IBEROAMERICANO Y VIII JORNADA “TÉCNICAS DE RESTAURACIÓN Y CONSERVACIÓN DEL PATRIMONIO" 10 e 11 de Setembro de 2009 - La Plata, Buenos Aires, Argentina. Resumo. Recife - PE: Fundação do Patrimônio Histórico e Artístico de Pernambuco - FUNDARPE, 2009.

E. A. Rocha, J. V. S. Macedo, P. Correia, E. C. Barreto Monteiro (2018), “Adaptação de mapa de danos para edifícios históricos com problemas patológicos: Estudo de Caso da Igrejado Carmo em Olinda PE.", Revista ALCONPAT, 8 (1), pp. 51 - 63, DOI: http://dx.doi.org/10.21041/ra.v8i1.198

LAGO, Gabriel. Catedral tombada como patrimônio histórico está infestada por morcegos. G1 TOCANTINS. Disponível em: http://g1.globo.com/to/tocantins/noticia/2016/09/catedral-tombada-como-patrimonio-historico-estainfestado-por-morcegos.html, 2016.

LERSCH, I. M. Contribuição para a identificação dos principais fatores de degradação em edificações do patrimônio cultural de Porto Alegre. (Mestrado e Engenharia Civil) - Programa de pós-graduação em engenharia civil UFRGS. Porto alegre, 2003.

MANDUCA, Talles. Tombamento do Centro Histórico de Porto Nacional. Porto Nacional 2007.

OLIVEIRA, Maria de Fátima. Um Porto no Sertão Cultura e cotidiano em Porto Nacional 1880/1910. Goiânia 1997.

REIS, Regina. A catedral de Porto Nacional- UCG- Departamento de Arquitetura e Urbanismo- Goiânia, 1983.

TINOCO, Jorge E. L. Mapa de Danos - Recomendações Básicas. Texto para discussão - Serie 2: Gestão de Restauro. Centro de Estudos Avançados da Conservação Integrada (CECI), Olinda, 2009. 


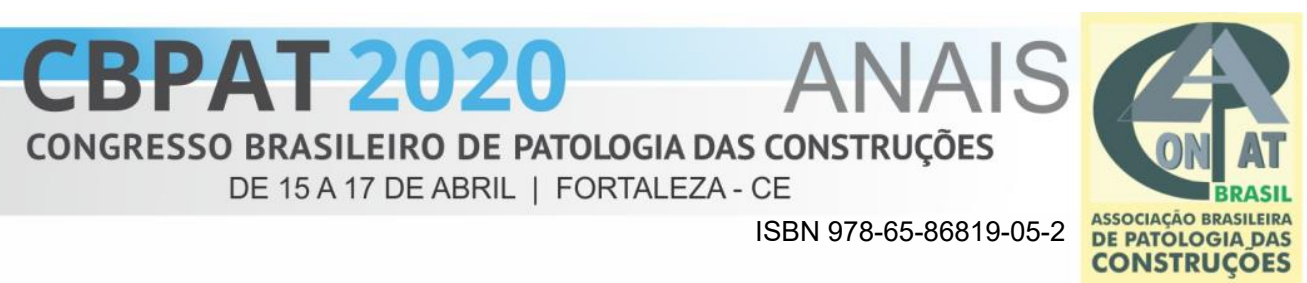

ZANCHETI, Silvio Mendes et al. Os limites do Restauro: Impasses Projetuais. Texto para discussão - Serie 2: Gestão de Restauro. Centro de Estudos Avançados da Conservação Integrada (CECI), Olinda, 2009. 